\title{
$O$ adiamento do projeto parental na contemporaneidade
}

\author{
Denise Bernardi*
}

\begin{abstract}
Resumo
O objetivo deste estudo é refletir acerca do adiamento do projeto parental na contemporaneidade. Para tanto, realizou-se uma revisão de literatura utilizando-se como base autores contemporâneos que pesquisam sobre o tema. Analisando o projeto parental sob uma perspectiva histórica, percebemos que o desejo de ter filhos e a procriação sofreram mudanças significativas ao longo do tempo. $\mathrm{Na}$ atualidade, observa-se que houve um declínio do projeto de ter filhos como principal objetivo do casal conjugal. Apesar do aumento do número de casais que adiam a parentalidade ou optam por não ter filhos, observa-se que é reduzida a produção cientifica acerca desta temática no cenário brasileiro. Constatou-se que, os casais atuais privilegiam seus anseios individuais, e somente após a realização destes analisam a possibilidade de incluir em seus planos o projeto parental.

Palavras chave: adiamento; parentalidade; filhos.
\end{abstract}

\section{The postponement of the parental project in contemporary}

\section{Abstract}

This study aims to reflect on the postponement of the parental project in the contemporaneity. For this, a literature review was carried out using as a basis texts from reference authors who research of the theme. Analyzing parental project from a historical perspective, it is observed the desire to have children and procreation have undergone significant changes over time. At present, it is observed that there has been a decline in the project of having children as the main objective of the conjugal couple. Despite the increase in the number of couples who postpone parenting or choose not to have children, it is observed that the scientific production on this subject in the brazilian scenario is reduced. It was found that current couples privilege individual desires, and only after their completion do they analyze the possibility of including in their plans the parental project.

Keywords: postponement; parenthood; children. 


\section{Introdução}

$\mathrm{Na}$ década de 1950, ter filhos era definido como um comportamento normal de todo adulto casado. A possibilidade de escolha acerca da parentalidade é um fenômeno contemporâneo que foi se consolidando no decorrer do século XX. A viabilidades dessa escolha foi influenciada por intensas transformações sociais, tais como o surgimento da pílula anticoncepcional, o movimento feminista, a inserção da mulher no mercado de trabalho e as modificações no casamento.

Ao longo da história, a sociedade enfatizou a parentalidade como um aspecto central para que as pessoas tivessem uma vida satisfatória, sendo que a vida daqueles que não tem filhos seria menos gratificante (Pollmann-Schult, 2014). Ter filhos culturalmente costuma ser percebido como um indício de que o relacionamento conjugal vai bem. A expectativa acerca da parentalidade é evidenciada também na literatura, que sugere que casais com filhos tem benefícios sociais e um aumento da longevidade (Modig, Talbäck, Torssander \& Ahlbom, 2017).

Entretanto, a parentalidade envolve uma infinidade de dificuldades em decorrência das exigidas transformações na rotina do casal. Estudos apontam que casais com filhos podem enfrentar uma diminuição da satisfação conjugal (Hernandez \& Hutz, 2009) e um aumento das demandas domésticas e financeiras (Pollmann-Schult, 2014; Barbiero \& Baumkarten, 2015), aspectos que podem impactar negativamente no relacionamento conjugal.

Esses fenômenos, parecem ter influência no aumento do número de casais que na atualidade adiam o projeto parental ou optam por não ter filhos (Blackstone \& Stewart, 2012). A sociedade valoriza e incentiva o sujeito contemporâneo a investir na vida acadêmica e manter-se ativo no mercado de trabalho, do mesmo modo espera que tenha filhos e dedique-se ao cuidado destes. Este impasse atrelado ao anseio do casal contemporâneo de adquirir melhor status social e estabilidade financeira antes de ter filhos, (Matos \& Magalhães, 2014), parece levar muitos casais a postergar a parentalidade.

Entretanto, apesar da aparente liberdade que o casal contemporâneo possui acerca da decisão de ter filhos ou quando tê-los, isso parece não os livrar dos constantes questionamentos sociais acerca deste projeto. Embora na atualidade tenha diminuído o estigma social acerca do casal sem filhos, ele ainda mostra-se presente (Sohne \& Wendling, 2011; Caetano, Martins, \& Motta, 2016).

No âmbito dessas considerações, este artigo, que consiste de uma revisão de literatura, tem por objetivo refletir acerca do adiamento do projeto parental na contemporaneidade.

\section{Método}

Para atingir o objetivo proposto no presente estudo, foi realizada uma revisão de literatura acerca da produção científica referente ao adiamento do projeto parental. Para tanto, utilizou-se como base autores contemporâneos que pesquisam sobre o tema, dando ênfase as investigações que comtemplavam as transformações no relacionamento conjugal, em especial, no que concerne a configuração de casais sem filhos.

As fontes privilegiadas para a pesquisa foram as bases de dados Scielo e LILACS, delimitando-se a busca por publicações dos últimos doze anos (2005-2017). Foram utilizados os seguintes descritores: casal, parentalidade, adiamento e projeto de ter filhos. Com estes foram feitas diversas combinações.

\section{Resultados e discussão}

\section{O projeto de ter filhos}

O desejo de ter filhos e a procriação sofreram significativas mudanças ao longo do tempo. Nas décadas de 1950 e 1960 as normas sociais estabeleciam que todo casal deveria ter filhos. Podia até optar-se por não tê-los, mas arcando com o ônus se ser socialmente criticado (Bardwick, 1981). Até a década de 1960, não ter filhos era algo predominantemente involuntário na vida de uma pessoa, sendo principalmente em decorrência do não casamento ou da infertilidade (Hagestad \& Call, 2007).

Algumas das principais mudanças ocorridas na estrutura da família aconteceram por volta dos anos 1960, com a chamada revolução sexual. O surgimento da pílula anticoncepcional neste período foi recebido com muita apreensão, pois prenunciava o fim da família tradicional, dos costumes e da moral (Ceccarelli, 2007; Osório, 2011).

Com o aparecimento de novas técnicas para acompanhar o parto e a gravidez, passou-se a problematizar a saúde e a quantidade de filhos, levando os casais à redução no número de filhos, diferentemente da família tradicional na qual não havia esse controle. Neste contexto, os casais passaram a ter mais liberdade de escolha e autonomia frente a suas decisões. A partir dos anos 1970, com o movimento feminista e suas críticas sobre o lugar da mulher na família e na sociedade, abriu-se um espaço para liberdade relativo à escolha da parentalidade, incluindo o direito de recusá-la (Rocha-Coutinho, 2013; 2015). 
Foi nessa época que surgiram os primeiros estudos sobre casais sem filhos. Em geral, tais estudos atribuíam a não parentalidade a um problema de ordem biológica, ligado a infertilidade (Bloom \& Pebley, 1982). Nesse periodo, não se investigava sobre a possibilidade de não ter filhos como uma escolha voluntária. Por meio dos avanços da medicina, que permitiram a dissociação entre sexualidade e procriação (Chatel, 1995), a conjugalidade passou a ser pautada, em especial, por escolhas pessoais. Com isso, aumentou o número de pessoas que passaram a escolher por não abdicar da relação à dois em prol da parentalidade, fazendo assim a opção de não ter filhos ou adiar este projeto (Rios \& Gomes, 2009; Lima, 2013).

De fato, o surgimento da pílula anticoncepcional e o movimento feminista, muito contribuíram para a abertura da possibilidade de escolha de ter ou não ter filhos. Entretanto, a realização da parentalidade sempre esteve articulada a discursos sociais e ideológicos, não dependendo apenas da capacidade reprodutiva de homens e mulheres (Nascimento \& Terzis, 2010). Isso porque, na base da identidade compartilhada entre o casal estaria a projeção de um futuro em conjunto, que é marcado pela expectativa de constituição familiar. Assim, na expectativa da continuidade geracional, espera-se que o casal conjugal gere um casal parental e que assim cumpra a "missão" de ter filhos (Magalhães, 2010).

Assim, apesar de atualmente os casais terem maior liberdade para decidir se querem ou não ter filho, já que sexualidade e procriação não mais se complementam (Chatel, 1995), eles continuam sendo questionados acerca deste projeto (Sohne \& Wendling, 2011; Caetano, Martins \& Motta, 2016). Em decorrência de a parentalidade ser culturalmente valorizada em nossa sociedade, a decisão de não ter filhos gera um sentimento de surpresa na maioria das pessoas (Leitão \& Ribeiro, 2007).

Neste sentido, aqueles que decidem adiar o projeto de ter filhos ou optam por não tê-los costumam vivenciar pressões sociais, uma vez que, ser diferente do que é socialmente esperado não costuma ser bem aceito. Assim, a escolha pelo adiamento ou a não parentalidade é, muitas vezes, interpretada como um comportamento egoísta (Caetano, Martins \& Motta, 2016).

Conforme já mencionado, a sociedade observa a parentalidade como algo central para que uma pessoa tenha uma vida significativa. Entretanto, o projeto ter filhos parece não ser mais o objetivo central na vida do casal contemporâneo. $\mathrm{Na}$ atualidade, observa-se que muitos assumem a opção de não ter filhos, ou desprivi- legiam a parentalidade em prol de outros projetos, em especial individuais.

A individualidade, marca da sociedade contemporânea, delineia um novo panorama para as relações conjugais. É possível que, em consequência da valorização da individualidade dos membros de um casal, novos sentidos estejam sendo associados à vida conjugal, gerando dificuldades na negociação e conciliação de desejos e expectativas individuais (Borges, Magalhães \& Féres-Carneiro, 2014).

\section{Ser casal: as transformações no casamento e na conjugalidade}

Nos séculos XVII e XVIII, o amor e o casamento não eram vistos como feitos um para o outro. O surgimento do casamento como instituição foi fundamentado na regulamentação de atividades de base biológica ligadas à reprodução (Diniz, 2010). Ao longo da história, no entanto, o casamento assumiu outras funções de ordem econômica e social.

O casamento passou por muitas transformações ao longo dos anos. Da antiguidade à idade média, eram os pais quem cuidavam do casamento dos filhos. Nesse período, o matrimônio não era percebido como um relacionamento amoroso, mas sim como um "negócio" entre famílias, um contrato firmado entre elas, visando benefícios próprios. Nessa época, os casamentos antecediam o início da relação e muitos aconteciam por obrigação ou interesses familiares. Diferentemente, hoje é o amor que tem que preceder o casamento, ele tornou-se condição para tal (Zordan, Falcke \& Wagner, 2009; Diniz, 2010).

As grandes mudanças no casamento se iniciaram com as transformações da modernidade, através do estabelecimento do casamento por amor, da valorização da individualidade, e da possibilidade de prazer na relação a dois. Esse novo "ideal" de casamento propôs aos casais a oportunidade de ter expectativas com relação ao amor e a felicidade no matrimônio (Borges \& Magalhães, 2013).

$\mathrm{Na}$ atualidade, observa-se um modelo de união em que predomina a relação igualitária entre os cônjuges, a valorização do companheirismo no vínculo conjugal, e a ausência de obrigações quanto à reprodução. A conjugalidade atual é influenciada pelos imperativos da intimidade, da individualidade e da privacidade, atributos característicos do sujeito moderno. $\mathrm{O}$ amor tem sido considerado um componente cada vez mais importante na relação conjugal, porém ele tem sido um ideal muito difícil de ser atingido (Féres-Carneiro \& Magalhães, 2005; Borges, Magalhães \& Féres-Carneiro, 2014). 
Percebe-se, que na atualidade há uma supervalorização das relações interpessoais e uma desvalorização da dependência entre os cônjuges. A conjugalidade é construída com base nos aspectos individuais de cada parceiro e se mantêm à medida que os cônjuges respeitam a individualidade um do outro (Singly, 2007; Borges \& Magalhães, 2013). Neste cenário, os projetos individuais passam a ocupar um lugar de destaque na relação à dois, assim como o livre-arbítrio e a felicidade pessoal começam a aparecer em primeiro plano (Matos \& Magalhães, 2014).

O questionamento sobre a rigidez das regras e dos papéis conjugais parece conduzir muitas pessoas na atualidade a postergar o casamento e o projeto de ter filhos. Reflete-se a respeito do impacto que a presença de um filho teria na rotina do casal, sobretudo quando os projetos individuais têm prioridade.

Cabe ressaltar, entretanto, que ainda é maior o número de casais que em algum momento de suas vidas se tornam pais. Apesar disso, tem havido uma crescente tendência entre eles em adiar o projeto parental ou optar por não ter filhos. Segundo dados do IBGE (2015), os arranjos familiares constituídos por casal com filhos vêm diminuindo nos últimos anos: em 2002, 52,7\% dos casais tinham filhos, em 2012 o índice já era de 45\%.

O declínio do número de casais que optam por ter filhos evidencia, assim, um aumento deste tipo de configuração familiar. Apesar de a configuração familiar de casais sem filhos ter aumentado, a temática do adiamento do projeto parental e da opção de ter filhos é pouco investigada no contexto brasileiro (Silva \& Frizzo, 2014; Biffi \& Granato, 2017).

\section{O adiamento do projeto parental}

A possibilidade de ultrapassar os limites biológicos e ampliar a vivência da parentalidade foi confirmada pelo avanço da medicina, que conferiu ao casal contemporâneo a oportunidade de decidir sobre a procriação. As novas técnicas de reprodução permitiram que a escolha de ter filhos pudesse ser estendida, e hoje mesmo que uma pessoa seja estéril, dependendo do caso, ela pode gerar um filho (Corrêa \& Loyola, 2015).

Embora as mudanças nos padrões reprodutivos tenham surgido inicialmente nos países desenvolvidos, a mesma tendência ocorre no contexto brasileiro (Biffi \& Granato, 2017). Segundo dados do Instituto Brasileiro de Geografia e Estatística - IBGE (2015) o número de mulheres que engravidaram pela primeira vez após os 40 anos cresceu $27 \%$ em 10 anos no país. Entretanto, apesar de a medicina ter possibilitado ao casal um maior controle sobre a decisão de quando ter filhos, o recurso da parentalidade tardia no Brasil ainda é limitado a uma categoria de nível sócio econômico mais alto, uma vez que, até o momento, as técnicas de reprodução no contexto brasileiro não são oferecidas pelo Sistema Único de Saúde (Braga \& Amazonas, 2007; Corrêa \& Loyola, 2015).

Estimativas revelam que apenas cerca de $5 \%$ da população mundial, decide voluntariamente não ter filhos e, portanto, não escolhe o papel de parental como desejável (Makuch, 2006). O projeto de ter filhos, desse modo, é algo desejado pela maioria dos casais, ainda que, muitas vezes, como um planejamento futuro.

Apesar do desejo pela parentalidade, importantes fatores parecem contribuir para a postergação deste projeto. Cabe refletir que grande parte dos casais que tem filhos pela primeira vez após os 40 anos de idade fazem parte de um segmento populacional com alta escolaridade (IBGE, 2015). Esse dado sugere que uma das razões pelas quais muitos casais optam por tardar a parentalidade esteja relacionado ao investimento na carreira e na formação educacional.

Neste panorama, observa-se que em decorrência da demora pela conquista de uma melhor estabilidade financeira, e das exigências do mercado de trabalho, que impõem constante investimento em formação superior, a decisão acerca de quando ter filhos torna-se cada vez mais difícil (Bernardi, Féres-Carneiro \& Magalhães, 2017). Cabe lembrar que, a chegada de uma criança no sistema familiar requer certo afastamento das atividades acadêmicas e profissionais, ainda que momentaneamente, em especial para a mulher. Assim, conciliar o investimento profissional com a maternidade/paternidade indica reorganizações para as quais, muitas vezes, os membros do casal se questionam estar preparados.

A inserção da mulher no mercado de trabalho parece, desse modo, ter importante influencia no adiamento do projeto de ter filhos (Lima, 2013; Rocha-Coutinho, 2013; 2015). Outro aspecto que parece influenciar na escolha dos casais em tardar a parentalidade, refere-se ao modo negativo como ela vez sendo referida na atualidade, em grande parte em decorrência dos custos financeiros que um filho tende a gerar (Stanca, 2012; Hansen, 2012). Neste viés, observa-se que a chegada de uma criança é relacionada à perda da autonomia dos cônjuges, que com a chegada do filho precisam abrir de suas prioridades, tais como comprar um carro, viajar ou investir em cursos de qualificação, em prol da parentalidade (Bernardi, Féres-Carneiro \& Magalhães, 2017). 
Soma-se a isto o fato de que na atualidade há uma tendência das novas gerações de prolongar as etapas do ciclo vital, tais como a adolescência e a saída da casa dos pais (Henriques, Féres-Carneiro \& Magalhães, 2016). Isso implica na automática postergação das reponsabilidades atribuídas ao mundo adulto, quer nas atividades profissionais ou mesmo na constituição de família.

\section{Considerações finais}

O presente estudo teve como objetivo refletir acerca do adiamento do projeto parental na contemporaneidade. Nesse viés, cabe pontuar que o cenário referente aos relacionamentos passou por intensas transformações ao longo da história. Valores como casar-se e ter filhos, que eram tradicionalmente esperados, na atualidade puderam ser flexibilizados. Apesar disso, o imaginário social ainda conserva a concepção de que a parentalidade seja almejada por todos os casais.

A sociedade preconiza que todo sujeito inclua em seus projetos o projeto parental. Por outro lado, a busca pela realização de projetos individuais, o investimento na carreira, e o tempo dedicado em qualificação profissional, parecem criar um impasse acerca do momento "ideal" para a inserção de filhos no relacionamento a dois. Culturalmente, a sociedade espera que um filho ocupe um lugar central na vida dos pais, tal aspecto, entretanto, pode ser visto pelo casal como um sacrifício, aspecto que parece favorecer o adiamento da parentalidade.

Em um contexto pautado por avanços da medicina e relacionamentos conjugais que priorizam escolhas individuais, tende a aumentar o número de pessoas que fazem a escolha de tardar o projeto de ter filhos. Diante desta realidade, cabe refletir sobre a importância de novos olhares acerca deste fenômeno.

Apesar de indiscutível a importância de estudos acerca do adiamento da parentalidade e o aumento do número de casais sem filhos, observa-se que é reduzida a produção cientifica acerca desta temática no cenário brasileiro (Rios \& Gomes, 2009; Biffi \& Granatto, 2017), em especial na perspectiva do homem (Bernardi, Féres-Carneiro \& Magalhães, 2017). A maior parte dos estudos investiga o adiamento da maternidade, ou seja, discute em especial a perspectiva da mulher. Nesse viés, sugere-se que sejam realizados estudos que se proponham a investigar o adiamento do projeto parental sob a ótica masculina.

Considerando a amplitude deste tema, acredita-se que este estudo constitui-se um ponto de partida útil para a realização de outros estudos acerca da temática em questão. Este trabalho procurou abordar alguns aspectos que servissem como norteadores para outras discussões que ainda precisam ser ampliadas.

Por fim, concluiu-se que na atualidade houve um declínio do projeto de ter filhos como principal objetivo do casal. Os casais atuais priorizam anseios individuais, e somente após a realização destes analisam a possibilidade de incluir em seus planos o projeto parental.

\section{Referências}

Biffi, M. \& Granato, T. M. M. (2017). Projeto de ter filhos: uma revisão da literatura científica nacional e internacional. Temas em Psicologia, 25 (1), 207-220.

Barbiero, E. B. \& Baumkarten, S. T. (2015). Somos pais, e agora?: A história de nós dois depois dos filhos. Pensando famílias, 19 (1), 32-45.

Blackstone, A. \& Stewart, M. D. (2012). Choosing to be childfree: research on the decision not to parent. Sociology School Faculty Scholarship, 5, 1-10.

Bardwick, J. M. (1981). Mulher, sociedade, transição: como o feminino, a liberação sexual e a procura da auto realização alteraram as nossas vidas. São Paulo, SP: DIFEL.

Braga, M. G. R. \& Amazonas, M. C. L. A. (2007). Mulheres, casais e famílias em suas experiências e aventuras com a reprodução assistida. In C. M. O. Cerveny (Org.), Família em movimento (pp. 37-76). São Paulo, SP: Casa do Psicólogo.

Bernardi, D., Féres-Carneiro, T. \& Magalhães, A. S. (2017). Entre o desejo e a decisão: a escolha por ter filhos na atualidade. Contextos clínicos, 11 (2), 22-35.

Bloom, D. E. \& Pebley, A. R. (1982). Voluntary childlessness: a review of the evidence and implications. Population Research and Policy Review, 1, 203-224.

Borges, C. C. \& Magalhães, A. S. (2013). Individualism, life trajectories and plans of constituting a family. Estudos de Psicologia, 30 (2), 177-185.

Borges, C. C., Magalhães, A. S. \& Féres-Carneiro, T. (2014). Liberdade e desejo de constituir família: percepções de jovens adultos. Arquivos Brasileiros de Psicologia, 66 (3), 89-103.

Caetano, C., Martins, M. S. \& Motta, R. C. (2016). Família contemporânea: estudo de casais sem filhos por opção. Pensando Famílias, 20 (1), 43-56.

Ceccarelli, P. R. (2007). Novas configurações familiares: mitos e verdades. Jornal de Psicanálise, 40 (72), 89-102.

Chatel, M. M. (1995). Mal estar na procriação: as mulheres e a medicina da reprodução. Rio de Janeiro, RJ: Campo Matêmico.

Corrêa, M. C. D. V. \& Loyola, M. A. (2015). Tecnologias de reprodução assistida no Brasil: opções para ampliar o acesso. Physis Revista de Saúde Coletiva, 25 (3), 753-777.

Diniz, G. (2010). O casamento contemporâneo em revista. In T. Féres-Carneiro, (Org.), Casal e família: permanências e rupturas. (pp. 135-155). São Paulo, SP: Casa do Psicólogo.

Féres-Carneiro, T. \& Magalhães, S. A. (2005). Conjugalidade dos pais e projeto dos filhos frente ao laço conjugal. In T. Féres-Carneiro, (Org.), Família e casal: efeitos da contemporaneidade (pp. 111-121). Rio de Janeiro, RJ: Ed. PUC-Rio.

Hagestad, G. O. \& Call, V. R. A. (2007). Pathways to childlessness - A life course perspective. Journal of Family Issues, 28 (10), 1338-1361.

Hansen, T. (2012). Parenthood and happiness: a review of folk theories versus empirical evidence. Social Indicators Research, 108 (1), 29-64.

Henriques, C. R., Féres-Carneiro, T. \& Magalhães, A. S. (2016). Ambivalence in adulthood: leaving the parental home. Estudos de Psicologia, 33(1), 5-14.

Hernandez, J. A. E. \& Hutz, C. S. (2009). Transição para a parentalidade: ajustamento conjugal e emocional. PSICO, 40(4), 414-421.

Instituto Brasileiro de Geografia e Estatística (2015). Síntese dos indicadores sociais. Rio de Janeiro, RJ: IBGE.

Leitão, D. O. \& Ribeiro, M. A. (2007). Filhos: ter ou não ter? O que influencia esta decisão? Pensando Famílias, 11 (2), 47-67.

Lima, M. G. R. (2013). Filhos? Só depois!: um retrato da mulher contemporânea. São Paulo, SP: Zagodoni.

Magalhães, S. A. (2010). Conjugalidade e parentalidade na clínica com famílias. In T. Féres-Carneiro, (Org.), Casal e Família: permanências e rupturas (pp. 205217). Rio de Janeiro, RJ: Ed. PUC-Rio.

Matos, M. G. \& Magalhães, S. A. (2014). Tornar-se pais: sobre a expectativa de jovens adultos. Pensando Famílias, 18 (1), 78-91. 
Makuch, M. Y. (2006). Gênero e reprodução assistida: novas fases e velhas questões. In R. Melamed, J. Quayle, (Org.), Psicologia e reprodução assistida: experiências brasileiras (pp. 21-34). São Paulo, SP: Casa do Psicólogo.

Modig K., Talbäck, M., Torssander, J. \& Ahlbom, A. (2017). Payback time? Influence of having children on mortality in old age. J Epidemiol Community Health, 71, 424-430.

Nascimento, F. \& Térzis, A. (2010). Adiamento do projeto parental: um estudo psicanalítico com casais que enfrentam a esterilidade. Psicologia em Revista, 16 (1), 103-124

Osório, L. C. (2011). Novos rumos da família na contemporaneidade. In L. C. Osório, \& M. E. P. Valle (Orgs.), Manual de terapia familiar: volume II (pp 17-26). Porto Alegre, RS: Artes Médicas.

Pollmann-Schult, M. (2014). Parenthood and life satisfaction: why don't children make people happy? Journal of Marriage and Family, 76, 319-336.

Rios, M. G. \& Gomes, I. C. (2009). Casamento contemporâneo: revisão de literatura acerca da opção por não ter filhos. Estudos de Psicologia, 26 (2), 215-225.

Rocha-Coutinho, M. (2013). A difícil arte de harmonizar família, trabalho e vida pessoal. In T. Féres-Carneiro, (Org.), Casal e família: transmissão, conflito e violência (pp. 13-33). São Paulo, SP: Casa do Psicólogo.
Rocha-Coutinho, M. (2015). Investimento da mulher no mercado de trabalho: repercussões na família e nas relações de gênero. In Féres-Carneiro (Org.) Familia e casal: parentalidade e filiação em diferentes contextos. Rio de Janeiro, RJ: Ed. PUC-Rio: Prospectiva.

Silva, I. M. \& Frizzo, G. B. (2014). Ter ou não ter? Uma revisão da literatura sobre casais sem filhos por opção. Pensando famílias, 18(2), 48-61.

Singly, F. (2007). Sociologia da família contemporânea. Rio de Janeiro, RJ: Editora FGV.

Sohne, L. C. \& Wendling, M. I. (2011). O significado de família para casais que optam por não ter filhos. Pensando Famílias, 15 (1), 117-137.

Stanca, L. (2012). Suffer the little children: measuring the effects of parenthood on well-being worldwide. Journal of Economic Behavior \& Organization, $81,742-750$.

Zordan, E. P. Falcke, D. \& Wagner, A. (2009). Casar ou não casar? Motivos e expectativas com relação ao casamento. Psicologia em Revista, 15 (2), 56-76.

Submetido em: 31-8-2018

Aceito em:26-7-2018 